\title{
Expectancy-Value Theory \& Preschool Parental Involvement in Informal STEM Learning
}

Tricia A. Zucker ${ }^{1}$, Janelle Montroy ${ }^{2}$, Allison Master ${ }^{3}$, Michael Assel ${ }^{1}$, Cheryl McCallum ${ }^{4}$, Gloria Yeomans-Maldonado ${ }^{1}$

${ }^{1}$ Children's Learning Institute, Department of Pediatrics, University of Texas Health Science Center at Houston

${ }^{2}$ Accelerate Learning Inc.

${ }^{3}$ Psychological, Health, \& Learning Sciences, University of Houston

${ }^{4}$ Children's Museum Houston

\section{Acknowledgements}

We thank the children, teachers, and research staff that made this work possible. Special thanks to Gabrielle Barnett, Charlene Brickner, Lorena Cortes, Karina Rodriguez-Figuerora, Gisela Trevino and Armando Orduano for their thoughtful work on this project. This research was supported by the National Science Foundation, Awards \#1811356 and DRL-1849902, and the U.S. Department of Education's Institute of Education Sciences, \#R305A200520. Corresponding author: Tricia Zucker, Children's Learning Institute, Department of Pediatrics, University of Texas Health Science Center at Houston, 7000 Fannin St., 2300, Houston, TX 77030. Email: tricia.zucker@uth.tmc.edu 


\begin{abstract}
Using expectancy-value theory we explored whether parents' perceived expectancies, value, and costs relate to involvement in STEM activities. We also explored whether informal learning varied based on child gender and parent's report of having a science, technology, engineering, and math (STEM)-related career. Moreover, we examined the mediator role of parents' expectancy, values, and cost of mother's STEM-related career and parental involvement. Our sample consists of 208 parents of 3- to 5-year-olds from mostly middle class families of diverse races/ethnicities. Controlling for sociodemographic factors, results revealed that only a parent's rating of STEM value, not expectancies or cost, was directly related to parental involvement in science and math. Maternal report of a STEM-related career was indirectly related to parental involvement in STEM through parents' higher self-efficacy for facilitating informal STEM learning. No significant relations were found for child gender. We discuss implications for supporting parents' involvement in early STEM.
\end{abstract}




\section{Expectancy-Value Theory \& Preschool Parental Involvement in Informal STEM Learning}

From the earliest ages, children are surrounded by opportunities to learn about science, technology, engineering, and math (STEM) by exploring how things work and why things happen the way they do. Parents play a critical role in their children's observations, exploration, and investigation of the world around them. Parents have daily opportunities to provide materials and create conversations that help children learn about nature, counting, building, tools, and other STEM concepts. Providing such experiences at an early age is critical, because early STEM skills lay the foundation for later learning (e.g., Duncan, Dowsett, et al., 2007). In fact, early investments in children's STEM education can have effects that compound over time (Heckman, 2006; Hulleman \& Barron, 2016).

Although children can build STEM knowledge and skills during formal schooling, informal learning experiences with parents provide additional and more varied chances for children to develop their STEM knowledge and abilities (Bell, Lewenstein, Shouse, \& Feder, 2009). For example, informal learning within play-based activities such as puzzles and blocks builds spatial skills that are valuable in later STEM learning (Newcombe \& Frick, 2010; Verdine, Golinkoff, Hirsh-Pasek, \& Newcombe, 2014). But more information is needed on STEM-related perceptions of parents of young children for facilitating these types of STEM activities. The current study focuses on psychological factors of preschool parents that may support or hinder parental involvement in informal science and math learning. Specifically, using expectancy-value theory of motivation (Wigfield \& Eccles, 2000), we examine potential positive supports as well as possible barriers parents may face in supporting science and math with young children. 


\section{Parental Involvement in Informal Learning}

Family involvement in learning is broadly beneficial to young children's early education outcomes (e.g., Ma, Shen, Krenn, Hu, \& Yuan, 2016; cf. Pomerantz, Moorman, \& Litwack, 2007). This study focuses on one dimension of family involvement - parental involvement in learning - that refers to parents engaging their children in various activities to promote intellectual development at home or during outside-of-school time (OST; Fantuzzo, Tighe \& Childs, 2000). This is synonymous with parents' home engagement in learning activities (i.e., self-reported behavioral frequency; Barnett, Paschall, Mastergeorge, Cutshaw \& Warren, 2020). Meta-analytic findings suggest that parental involvement in learning significantly influences children's academic achievement from preschool through high school with small to moderate effects (Castro et al., 2015; Jeynes, 2012; Ma et al., 2016). In a study of Head Start preschoolers, parental involvement in OST learning (e.g., reading at home, providing materials for learning at home) was found to have the strongest association with children's learning outcomes when compared to other parent behaviors such as volunteering at school or conferencing with the teacher (Fantuzzo, McWayne, Perry \& Childs, 2004). We are particularly interested in understanding parental involvement in STEM activities that range from math concepts (e.g., counting objects, comparing size of objects) to science and engineering knowledge and concepts (e.g., talking about weather/seasons, observing animals and plants, noticing patterns, using logic to play games).

By the time children enter preschool there is tremendous variability in their math and science knowledge (e.g., Bullock, Sodian, \& Koerber, 2009; McWayne, Cheung, Wright \& Hahs-Vaughn, 2012; von Hippel, Workman \& Downey, 2018) that influences their future rates of learning (Dumas, McNeish, Sarama \& Clements, 2019). Both the frequency and quality of 
parental involvement in math and science activities explains some of this variability (e.g., Levine, Suriyakham, Rowe, Huttenlocher \& Gunderson, 2010; Ramani, Rowe, Eason \& Leech, 2015; Skwarchuk, 2009). The frequency of home learning activities (e.g., cognitive stimulation, shared book reading) within nationally representative samples of young U.S. children consistently predicts children's cognitive development (e.g., Barnes \& Puccionio, 2017; Barnett et al., 2020; Powell, Son, File \& Froiland, 2012). Qualities of parent-child interactions influence learning and also socialize the child to understand the family's cultural norms, interests and expectations (Grusec \& Davidov, 2010; Le et al., 2008; Ramani et al., 2015). From early childhood through the elementary grades, parents' support for teaching math concepts and high expectations for academic achievement are key characteristics of effective parent-child math interventions (Castro et al., 2015; Levine et al., 2010; Klein, Starkey, Clements, Sarama \& Iyer, 2008).

Parents can "do science and math" within their everyday routines or play. For example, during math-related play, parents can talk about numeracy (Gunderson \& Levine, 2011; Levine et al., 2010; Napoli \& Purpura, 2018) and number operations (Skwarchuk, 2009; Levya et al., 2017). When exploring science-related topics, parents may support children's cognition and engagement with descriptive talk, open-ended questions, and by encouraging inquiry (e.g., Callanan, Castañeda, Luce \& Martin, 2017; Haden, 2010; Leichtman et al., 2017; Tenenbaum, Snow, Roach \& Kurland, 2005). However, despite the opportunities to engage in math and science at home, parents tend to report more home literacy than STEM-related activities. Some STEM researchers suggest this is because parents in North America have heard the message it is important to read daily to young children, but they perceive that doing science and math is not as important to focus on every day (Skwarchuk, 2009; Skwarchuk, Sowinski \& LeFevre, 2014). 
Data from the Programme for International Student Assessment (PISA) and other international sources show there is tremendous variability around parental involvement in science versus literacy involvement (e.g., Ho, 2010; Manolitsis, Georgiou \& Tziraki, 2013). Further, data from the Early Childhood Longitudinal Study, Kindergarten Class of 2010-11 (ELCS-K: 2011) suggest that parents of kindergarten children engage in literacy-related activities at higher frequencies than science-related activities. Specifically, 51\% of parents of kindergarten children reported reading books to their child every day, while only $12 \%$ of parents reported talking about nature or doing science projects with their child with the same frequency.

\section{Expectancy-Value Theory Applied to Parents' Science \& Math Perceptions}

We investigated how parents' motivation relates to parental involvement in informal STEM learning (Eccles, 2015). Expectancy-value theory (EVT; Wigfield \& Eccles, 2000; Wigfield \& Gladstone, 2019) offers a multidimensional approach to describe parent motivation to support OST learning. The first EVT dimension is expectancy, or the perceived likelihood of achieving a desired outcome. We examined two aspects of expectancy: a) parents' expectancies for how well their child will do in math and science; and b) parents' expectations of how well they can guide and facilitate their child's learning within STEM tasks. This second aspect is also referred to as parental self-efficacy, meaning the parent's perceived ability to positively support their child's learning and development (Bandura, 1997; Le et al., 2008). The second EVT dimension is value, or the importance of the task to the individual. For example, some parents see value in reading with their preschooler but perceive less utility or enjoyment in doing science and math activities with their child (Skwarchuk, 2009). The final dimension of EVT is cost or the perceived efforts, loss of time for alternative activities, or negative emotional impacts that may hinder motivation (Flake, Barron, Hulleman, McCoach \& Welsh, 2015). For example, some 
parents may have had troublesome math experiences as students that produce continued math anxieties or other negative emotions (Bekdemir, 2010). The combination of parents' STEM expectancies for their child, parental self-efficacy, values, and costs is expected to influence the choice of whether to be involved in OST learning activities (Šimunović \& Babarović, 2020).

The EVT framework has been extensively applied to elementary- through college-age students to explain their STEM interest and achievement (e.g., Bergey, Parrila, \& Deacon, 2018; Eccles, 2007; Gaspard et al., 2015; Hulleman \& Harackiewicz, 2009). Young children's STEM interest is influenced by parent beliefs, as parents' perceptions are a means of socialization around how families do science and math (Lee \& Shute, 2010; Wang \& Degol, 2013). For example, in nationally representative U.S. samples, parental expectations of young children predict kindergarten math achievement as well as children's later expectations of self in Grade 8 (Froiland, Peterson \& Davison, 2013). In fact, one study found that parents' STEM expectancies were a more powerful predictor of elementary science achievement than teachers' or children's own expectancies (Thomas, 2017). Likewise, international data show that higher parental value of science (i.e., broad value of science to society, personal value of science, importance of science for jobs) predicts students' science achievement (Perera, Bomhoff \& Lee, 2014; see also Harackiewicz, Rozek, Hulleman, \& Hyde, 2012). Finally, perceived costs can lead to avoidance or procrastination (Jiang, Rosenzweig \& Gaspard, 2018). It is plausible that parents' perceived costs (effort costs, opportunity cost) could prevent them from doing math and science with their child or doing STEM with negative affect. Yet all of these parental beliefs are malleable factors that can be enhanced with early interventions and that may mediate intervention effects (e.g., Loughlin-Presnal \& Bierman, 2017). Thus, it is important to understand parental beliefs towards STEM, as interventions to enhance low STEM expectations will be quite different than those that 
aim to increase the perceived value of science and math. By targeting parental beliefs with the strongest links to parental involvement, we can increase the effectiveness of future interventions.

\section{Potential Discrepancies in parental Beliefs Depending on Child Gender}

Parents' involvement in STEM activities with their children may be influenced by many socio-cultural factors, including cultural stereotypes about gender and STEM (Jacobs \& Eccles, 1992; Tiedemann, 2000). Stereotypes are beliefs linking groups with particular traits or characteristics, such as the belief that STEM is "for boys," or that boys are better than girls at STEM (Master \& Meltzoff, 2020). If parents believe that STEM activities are more genderappropriate for boys, it may distort their perceptions of their child's potential to succeed in STEM (Eccles, 1993). They may spend more time and involvement on STEM activities with sons than daughters (Gunderson, Ramirez, Levine, \& Beilock, 2012; Jacobs, Davis-Kean, Bleeker, Eccles, \& Malanchuk, 2005). Even parents of young children endorse these stereotypical beliefs (Lummis \& Stephenson, 1990). Previous findings on parental involvement in STEM activities based on child gender have been mixed. Some studies have found that parents underestimate elementary- and middle-school-aged girls' interest in science (Ford, Brickhouse, Lottero-Perdue, \& Kittleson, 2006; Tenenbaum \& Leaper, 2003), and spend less time talking about science to girls than boys between ages 1 and 8 (Crowley, Callanan, Tenenbaum, \& Allen, 2001). However, other studies have found no differences in the math materials that mothers give to elementary-school children (Simpkins, Fredricks, \& Eccles, 2012). We explored potential gender differences in parents' STEM involvement and perceptions for their preschoolers.

\section{Parent's Own STEM Background and Relations to Motivation for Informal Learning}

Parents' experiences with STEM and identity as someone who uses STEM in their career may influence their beliefs and involvement in their child's math and science learning. The 
decision to pursue a STEM-related career is influenced by multiple components such as psychological beliefs (values, goals, and interests), socialization influences (social and cultural experiences) as well as individual abilities (Wang \& Degol, 2013). Parents' own childhood home environments likely relate to whether they enrolled in college and/or pursued STEM careers (Degol, Wang, Ye \& Zhang, 2017; Rozek, Svoboda, Harackiewicz, Hulleman \& Hyde, 2017). For example, a longitudinal study showed that participation in an intensive after-school, science museum program during high school influenced college matriculation and pursuit of STEM, medical and health-related careers (Fadigan \& Hammrich, 2004). Parents with STEM-related careers may have taken proactive steps to support their own science and math interest and learning (e.g., Patall et al., 2019) that, in turn, could make science and math topics more personally relevant and promote their child's identity as someone who could hold a future STEM-related career (cf. Hulleman \& Harackiewicz, 2009). When a parent does math and science activities with their young child, they bring conscious and unconscious motivations about math and science that are likely influenced by their own career pathway (Dorsen, Carlson, \& Goodyear, 2006). As parents who attained a STEM-related career bring considerable STEMrelated training, coursework, and experiences to all parent-child interactions, this study investigated direct and indirect influences of parents' STEM-related career on their involvement with informal STEM learning.

\section{Current Investigation Goals \& Hypotheses}

As stated, the current study uses EVT to understand the science and math beliefs of parents of preschool-aged children and how these parental perceptions relate to parents' involvement in their child's STEM learning. Our sample was somewhat diverse with mostly middle-class parents. This survey research using EVT of motivation can inform interventions 
aimed at increasing parental involvement in science and math learning outside of school. This study focuses on the quantity of parental involvement in learning, recognizing that frequency of interactions relates to quality (e.g., Barnett et al., 2020). As a secondary interest, we compared the frequency of parental involvement in STEM activities to literacy activities. We examined the following descriptive and correlational research questions (RQ):

1. How often do parents of preschoolers engage in STEM activities within this sample? How does this compare to the reported frequency of literacy activities?

2. How do parents' expectancy, value, and cost relate to quantity of self-reported parental involvement in informal STEM learning activities?

3. Does child gender relate to parental value, expectancy, cost, and involvement with STEM?

4. Does parental participation in a STEM career relate to parental value, expectancy, cost and involvement with STEM?

For the descriptive question RQ1, we expected frequent parental report of STEM activities such as counting or talking about weather/seasons, but that this would be less frequent than reported literacy activities (Skwarchuk, 2009). For RQ2, we hypothesized that as parental expectancy and value increased, parental self-reported involvement in STEM learning would be more frequent; conversely, as perceived costs increased we expected parental involvement would decrease (e.g., Powell et al., 2012). For RQ3, given the broader cultural milieu around gender stereotypes (Master \& Meltzoff, 2020), we hypothesized that parents may have different values and expectations of boys relative to girls for STEM. For RQ4, although we recognize parents' interest and ability to obtain a STEM-related career was likely to relate to higher value and expectations for STEM (Wang \& Degol, 2013), we did not have a directional hypothesis for 
costs. That is, we realize some potentially demanding STEM occupations could increase and/or decrease perceived opportunity costs of taking time for informal STEM learning activities.

\section{Methods}

\section{Procedures}

Survey participants were recruited through two primary methods - online and face-toface within a children's museum. Over a 7-week period (Feb. 7, 2019 to March 28, 2019), research staff solicited survey responses. Researchers used an IRB-approved, passive consent process that invited families of 3- to 5-year-old children to complete a 10-minute survey that was introduced by explaining, "We want to learn more about what parents of young children think about doing science and math at home. Understanding parents' thoughts and needs will help us develop better materials to support learning at home." The majority of responders completed an online survey via Qualtrics that was sent to a database of families registered at [blinded/name removed.org]. The [blinded/name removed.org] is a University owned website that had 23,320 public access users (educators, school administrators, parents) at the time of the study. This website is used by families to: (a) learn about developmental milestones and screening, or (b) access learning activities for families with children from birth through kindergarten. We filtered the registered users to only send the survey to parents of 3- to 5-year-olds. Before beginning the survey, a screening question asked if the parent had a child who was currently preschool aged; if this response was "no," the survey did not advance to additional items. Initially, 3,258 emails were sent with an invitation to the survey; amongst those 73 emails failed or bounced back, resulting in 3,158 online invitations. From these, 168 completed surveys were registered, representing a $5.27 \%$ response rate for online surveys. 
Research staff also collected written survey responses during five museum visits on Thursday nights when museum entrance is free. The Children's Museum [blinded/location removed] hosted more than a million visitors during this year. Researchers attended a story time in the museum library and invited parents to complete the survey before and after this readaloud. An exact response rate could not be determined because not all families attended the entire storytime; however, this method resulted in 40 surveys amongst 100 parents invited, representing approximately a 40\% response rate for face-to-face survey collection. Although 257 parents answered at least some survey questions (across online and face-to-face modalities), only 208 completed the majority of survey items (i.e., may have skipped 1-5 questions, such as income questions) and could be used in analyses. Note that $100 \%$ complete survey data was provided by 185 parents.

\section{Participants}

The final sample included 208 participants. Mothers were the most common survey participants (67\%). Participants reported on both mother and father's education and careers. Although there is some diversity in this sample, the maternal education and household income levels were mostly middle class. For mothers, over 70\% reported a Bachelor's degree or higher, see Table 1 . There was some income variability with $14 \%$ reporting below $\$ 30,000$ and $45 \%$ of respondents reporting over $\$ 100,000$ a year. Note that income was an option field completed by $70 \%$ of participants. We also asked participants to self-report whether they currently held a STEM career. For occupation, 44\% of mothers reported working in a STEM career (e.g., engineer, nurse, data analyst, researcher) vs. non-STEM (e.g., human resources, reading specialist, curriculum writer, stay-at-home mother), and $48 \%$ of fathers. In most families only one parent was in a STEM career $(n=77)$, or no parents were in STEM careers $(n=63)$, but a 
number of families reported both parents were in STEM careers $(n=48)$ and some data were missing $(n=20)$. Parents were also asked several questions regarding home language. As detailed in Table 1, 40\% indicated that they spoke a language other than English at home. Children were considered dual language learners (DLLs) if their parents reported speaking a language other than English in the home. For DLLs, the most common language spoken was Spanish (59\%). There were sixteen other languages represented in the sample. These preschool children were $48 \%$ female and represented diverse race/ethnicities: 48\% White/Caucasian, 25\% Hispanic or Latino/a, 11\% Black/African American, and 6\% responded 'Other.'

\section{STEM Survey Development \& Psychometrics}

The survey included 40 initial items about STEM learning and additional reading items detailed in the Online Supplemental Appendix A1. The first 10 items addressed parental involvement in STEM activities over the past week, using an 4-point rating scale (1-Not at all; 2Once or twice; 3-Three or more times, but not every day; 4- Every day). Sample items include: "How many times in the past week have you compared sizes of objects or toys with your child?" "How many times in the past week have you talked to your child about plants, animals or other living things?" The parental involvement items were adapted from the Head Start Family and Child Experiences Survey (FACES; West et al., 2009); these same items have been used in other nationally representative samples such as the Early Childhood Longitudinal Study (ECLS) to permit comparisons. We added items that used the same structure to ask about additional math and science activities.

The remaining 30 items were based on EVT and were designed to assess parents' perceptions about STEM for their child, including items related to: (a) parental expectancy for their child's success with STEM activities; (b) parental self-efficacy for supporting their child's 
STEM learning; (c) parental value of STEM knowledge; and (d) items related to costs of doing informal STEM learning. These items had 7-point rating scales with two different types of anchors. For example, some items (e.g., "In the job market it helps to have good math knowledge and skills") used this scale: 1-Strongly Disagree, 4-Neither agree nor disagree, 7-Strongly agree. Other items (e.g., "Because of the other things I have to do, I don't have enough time for doing math with my child") used this scale: 1 -Not true at all, 4-Neutral, 7-Very true. Some items from the PISA (2006) were used, and items were adapted from other studies that used EVT with other populations (e.g., Jiang et al., 2018). In addition, we included some literacy-related items that were not part of the primary analyses; these items were designed to reduce parents' social desirability to rate STEM involvement and motivation highly because it was presented in isolation and to provide a comparison to literacy activities. For example, the literacy involvement items asked about how often in the past week parents read to their child or taught their child about writing or letters; see all items in Online Supplementary Table A2.

STEM survey instrument properties. Rather than scoring by theoretical distinction (e.g., grouping all cost items into a sum score), we used Exploratory Factor Analyses (EFAs) to evaluate whether the items described several latent constructs as expected. EFAs are often used to test whether survey questions represent a latent construct as expected, and can provide initial construct validity evidence (Tabachnik, Fidell, \& Ullman, 2007). We conducted an EFA in Mplus 7.2 (Muthen \& Muthen 1998-2012) using a maximum likelihood estimator to account for missing data and a Geomin rotation (allowing for correlated factors). Akaike (AIC) and Bayesian Information Criteria (BIC), as well as eigenvalues and model interpretability, were used to assess what factor solution best fit the data, with smaller numbers indicating better fit. Results suggested a five factor model, see Table 2 for a comparison of different factor solutions via the 
AIC and BIC. AIC and BIC fit statistics were lower for the five factor model than the prior lower factor solutions. The first four factors had eigenvalues greater than two. The fifth factor's eigenvalue was 1.98 , but this solution was more interpretable than the four factor solution and so it is described below. We also considered a six factor solution; however, the added factor only included cross loadings and was not interpretable. The final five factors are parental involvement, parental expectations of child, parental expectation of self (self efficacy), parental value, and parental cost, please see Table 3 for all survey items and factor loadings. These factors related closely to the expected constructs and aligned with Eccles and colleagues' EVT motivation theory. However, as noted under Table A1, although most items included in the EFA loaded clearly to one factor, three items cross loaded on both the parental expectation of self factor and the parental expectations of child factor (with lower but also significant loadings on other factors too). As these items did not fall cleanly on a factor and included multiple high cross loadings, they were excluded from the structural equation model presented below.

\section{Statistical Analyses}

We use the five factors as part of a structural equation modeling approach to evaluate potential predictive associations between parent reported expectancies, value, and cost (independent variables, IVs), and parent reported STEM involvement (dependent variable, DV DV). We allowed residual correlations between items that had the same root (e.g., "I think my child will receive good math/science grades in K;" "When I help my child learn math/science I feel comfortable") if they were indicated in model indices as improving fit within the SEM model. We predicted value and expectancy (including parental expectations of child and parental self-efficacy) would positively predict parental STEM involvement, while cost would negatively predict (RQ2). Thus, we built an SEM model with the parental involvement factor regressed on 
the cost, value, and expectancy factors. Next, to evaluate the role of child gender on parental reported value, expectancy and involvement (RQ3), we include child gender ( $0=$ girl) as a predictor of the value, expectancy, and involvement factors. Finally, we added parent STEM career to the model to evaluate the predictive role of the parent's career on expectancy, value, cost and involvement (RQ4). We also tested several exploratory mediation relationships using bootstrapped direct and indirect effects, as this approach has been shown to provide the most appropriate confidence intervals among currently available techniques (Hayes, 2009; MacKinnon, Lockwood, \& Williams, 2004; Preacher \& Hayes, 2008). Specifically, we tested whether parent STEM career affected involvement through increased parental value and expectancy. Family income and whether the parent was monolingual (reported English only) or bilingual (reported any language[s] in addition to English) were included as covariates.

\section{Results}

\section{RQ1: What are parents' reported levels of STEM involvement and motivation?}

Descriptive statistics for each EVT factor in Table 4 indicate that parents had high selfefficacy $(M=5.82, S D=1.37,1=$ Strongly disagree, $7=$ Strongly agree $)$, and similarly high expectations for their children $(M=5.57, S D=1.20,1=$ Not true at all, $7=$ Very true $)$. Parents generally did not report high costs of doing STEM $(M=2.32, S D=1.62$, which corresponds to "mostly untrue"). Notably, parents perceived a slightly higher value of doing science/math $(M=$ $6.36, S D=0.84,1=$ Not true at all, $7=$ Very true $)$ compared to STEM expectancies $(M=5.57$ for expectations of child; $M=5.82$ for parent self-efficacy). This was true for the overall factors (Table 4) as well as the item-level data reported in Online Table A1. There was also less variability in seeing STEM as valuable and important compared to the two expectancy factors. 
As shown on the right side of Table 4, There were no significant differences between responses of parents of boys versus girls (see Table $4 ; p \mathrm{~s}>.05$ ) across all factors (also see item level means by gender in Online Supplementary Table A1).

For involvement in STEM activities, parents in this mostly middle-class sample reported an average score of $2.59(S D=0.93,1=$ Not at all, $4=$ Everyday $)$, corresponding to supporting their child's informal science and math learning about two or three times per week, but not daily. Item level descriptives on parental involvement are available in Online Table A2. These data show the least common STEM activities include talk about force/motion and board games (corresponding to once or twice per week) whereas the most frequent items were counting and talking about weather/seasons (three or more times per week). However, parents varied in the frequencies they reported, ranging from not engaging in these activities at all to daily involvement in STEM as well as literacy activities such as reading books. Notably, $56 \%$ of parents reported reading everyday with their child, but only $35 \%$ reported any daily STEM activities, even for the most frequently occurring items (counting and talking about living things). Like most STEM-related items, didactic literacy activities of teaching about letters and writing were unlikely to occur daily (see Online Supplemental Table A3). As expected, parental involvement in STEM was positively correlated with parent expectations of child $(r=.20, p<$ $.05)$, parent self-efficacy $(r=.40, p<.05)$, and parent values $(r=.30, p<.05)$, and negatively correlated with cost $(r=-.15, p<.10)$; seeTable 5 .

\section{RQ2: How does parents' EVT motivation relate to parental STEM involvement?}

We tested whether parent reported value, cost, and expectancy predicted parent-reported involvement. In this first model, only direct associations between the factors were tested 
(controlling for covariates). Parent value significantly predicted parental involvement $(\beta=0.19$, $p<.05)$, so that for every one unit increase in parent's reported value (e.g., importance for child to learn math/science; value of STEM knowledge/skills for the job market), there was a 0.19 standard deviation increase in parental STEM involvement. Parents' self-efficacy also predicted parental involvement $(\beta=0.36, p<.01)$ such that when parents reported higher levels of comfort when helping children with math or science (or more materials), this was associated with more STEM- related activities with children during the week. No other association was significant; that is parental expectancy of their child and perceived costs of doing science and math did not relate to involvement in informal STEM activities.

\section{RQ3: Does child gender relate to parental value, expectancy, and involvement with STEM?}

Next, we tested whether the associations between parent self-efficacy, parent expectations of child, and values differed based on whether the child was male or female. Consistent with the means displayed in Table 4, child gender was not significantly associated with any parent report factors within the current sample, although there was a non-significant trend related to parental self-efficacy, suggesting parents may feel more efficacious when supporting their sons $(\beta=0.15, p=0.06)$. We note that the lack of gender difference is generally consistent with the larger field results suggesting that associations between child gender and parental beliefs about STEM often manifest later in development (Eccles et al., 1990; Šimunović \& Babarović, 2020).

\section{RQ4: Does a parent STEM career relate to parental motivation and involvement?}


Finally, we examined whether a parent's self-report of whether maternal or paternal careers were "STEM related" or not affected parent reports of EVT motivation and STEM involvement. This included testing whether there was an indirect effect from career to parental involvement through parent reported expectancies, value, and cost factors. Results indicated that paternal STEM-related career was not related to any factor within the model, and thus it was trimmed from the model and we do not discuss it further. However, as can be seen in the final model displayed in Figure 1, maternal STEM-related career was directly associated with parental self-efficacy $(\beta=0.24, p<.01)$. That is, when a parent reported that the mother's career was STEM-related, this related to higher feelings of efficacy when engaging in informal STEM learning. No other direct associations were significant, suggesting maternal STEM-related career was not directly associated with reported EVT or parental involvement. However, the mediation analyses suggest an indirect relationship between maternal STEM career and parental involvement through higher self-efficacy for supporting their child's informal STEM learning ( $\beta$ $=0.10,95 \%$ CI $[0.03-0.19]$. Specifically, the results suggest that mothers in STEM careers were more comfortable and had more materials related to science and math. This, in turn, led to higher reported involvement. No other indirect pathways were significant. In the final model (with the inclusion of the indirect effects), the direct association between parent values and Involvement dropped in significance to $p=.09$ (without the indirect effect the p-value $=.04$ ); however we note the standardized coefficient is the same $(\beta=0.19)$ in both models.

\section{Discussion}

This study used expectancy-value theory (EVT; Wigfield \& Eccles, 2000) to understand parents' motivations for engaging in informal science and math learning with their child. We identified higher parental value of science and math as well as parent self-efficacy as key 
predictors of parents' STEM involvement in this mostly middle-class sample. We also identified parents' self-efficacy as a mediator of parental involvement, but only for mothers in STEMrelated careers who espoused higher expectations of success for themselves in facilitating their child's math and science learning. A favorable finding was that gender stereotypes did not influence parents' perceptions or involvement in STEM with their preschool children. We discuss below how these and descriptive findings around frequency of parental involvement in STEM inform early interventions.

\section{Frequency of STEM Learning at Home}

In this mostly middle-class, U.S. sample, $56 \%$ of parents reported reading everyday with their child, but only 35\% reported engaging in any daily STEM activities. For comparison, in the Early Childhood Longitudinal Study (ECLS) that recruited a nationally-representative U.S. sample of preschool children, $45 \%$ of parents reported reading daily with their preschool children (Barnett et al., 2020). For kindergarten children, the ECLS-K: 2011 reports that $51 \%$ of parents read to the children daily. In our survey, $36 \%$ of parents reported talking about nature daily, and about $28 \%$ reported talking about weather, seasons, and the environment with the same frequency. In contrast, the ECLS-K: 2011 includes a related item asking parents how often they talk about nature or do science projects with children; about $12 \%$ of parents reported the frequency of this item as "every day." Unfortunately the ECLS datasets did not comprehensively assess math and science involvement to permit direct comparisons with our data. That is, we included new items assessing parental involvement in STEM but followed the same ECLS item structure and scale. Our descriptive findings align with evidence from Canadian samples that parents are more frequently engaged in literacy activities with their young child than math (Skwarchuk, 2009; Skwarchuk et al., 2014). Yet in some European countries, parental 
involvement in early numeracy and math activities may be more frequent than literacy activities (Manolitsis, Georgiou \& Tziraki, 2013).

There could be several reasons that parents in North America appear to devote more attention to literacy than math. First, it may be that these parents experience frequent literacy campaign messages that emphasize the importance of shared reading and talking about letters to be ready for school (e.g., Zuckerman, 2009). Second, it could be that these parents perceive science and math learning as a formal, didactic activity, whereas literacy activities like shared reading feel like more informal, naturalistic activities that are more feasible to integrate into the home environment (Early Childhood STEM Working Group, 2017; Skwarchuk et al., 2014). Early family programs at museums, schools, libraries or other community centers could help parents to recognize things they are already doing that are STEM-related. For example, common household items can promote talk about math (e.g., counting or subtracting grapes or crackers on a plate as you eat them; using kitchen equipment to measure quantities) and everyday routines can naturally promote science learning (e.g., observing bugs and birds during a walk; pointing out patterns in seasons and weather).

Given past evidence that preschool parental involvement in home literacy and numeracy activities bidirectionally supports children's broad school readiness across language, literacy, and math outcomes (e.g., Napoli \& Purpura, 2018), it is important to increase parental involvement in both literacy and STEM activities through family communications and programs. Some longtime national campaigns for U.S. parents, such as Reach Out and Read within pediatric clinics, are exploring ways to add math to their established literacy promotion, but implementation is not yet widespread (e.g., Jones et al., 2015). It is also particularly important to consider tailoring STEM messaging and programs for families experiencing poverty or other 
vulnerable populations. The frequency of home learning activities is known to be more important for children experiencing poverty or with weak initial skills, as it can serve as a protective factor for their cognitive development (Barnett et al., 2020; Powell et al., 2012).

\section{EVT \& Parental Motivation for Doing Science and Math}

In this sample, we found that parents' value of STEM and self-efficacy for facilitating STEM were the EVT factors that directly predicted involvement in STEM during OST. The items assessing value asked parents to rate broad math and science importance as well as STEM utility for future jobs using items that were adapted mostly from the PISA. Syntheses of EVT research suggest that value-related beliefs are the strongest predictors of achievement and career goals related to STEM (Wang \& Degol, 2013). Therefore, it is promising that parents' values were relatively high, as they are likely to socialize their children to also see value in STEM learning (Grusec \& Davidov, 2010). Frequently doing science and math activities together is a way for parents to send a message to children about how much they value STEM. The items assessing parental self-efficacy tapped into parents' perceived readiness to support their child's math and science learning at home. When parents feel likely to succeed in facilitating STEM learning, they may socialize their child to see science and math as enjoyable or may confidently guide their child's learning. For example, there is evidence that STEM activities with young children are more beneficial when parents use fewer directives and more open-ended inquiry questions (Haden, 2010; Levya et al., 2017). Indeed, with older children, parents' negative emotions or overcontrolling behaviors can be unhelpful (e.g., Patall, Cooper \& Robinson, 2008; Silinskas \& Kikas, 2019). Thus, preschool family interventions should capitalize on parents’ perceptions of STEM as relevant and valuable (cf. Hulleman \& Harackiewicz, 2009) and further explicate how adults can effectively guide children's STEM learning (McClure et al., 2017). 
Although the finding of greater self-efficacy for mothers who report being in a STEMrelated career is somewhat intuitive, we did not hypothesize that this would mediate the frequency of parental involvement in science and math. It is well established that parental selfefficacy, or parents' perceived ability to positively support their child's learning in a given task, influences behavioral choices (Bandura, 1997; Le et al., 2008). And it is also well-established that pursuing a STEM-related career is associated with learning and career pathways that require high motivation and persistence, particularly for women who often face systemic obstacles in these pursuits (Degol, Wang, Ye, \& Zhang, 2017; Wang \& Degol, 2013). Thus, our mediation finding is an interesting extension of existing evidence that mothers who have obtained a STEM career feel more confident in facilitating early STEM learning that, in turn, influences these parents' decision to engage in science and math learning with their preschooler. There are increasing models of effective STEM interventions designed to increase parental self-efficacy (Hollingsworth-Latimer, 2020) and parents' ability to show the value and relevance of STEM to their child (Rozek et al., 2017).

Parental expectations of the child and perceived costs were two EVT factors that were not significantly related to these parents' involvement in STEM. Parents reported few costs/barriers to doing STEM with most parents reporting that it did not take too much effort or time to do science and math. Turning to expectations of their child, most parents held positive expectations that their child would do well in science and math; however, these expectancies did not relate to parental involvement as we would have expected based on the strength of this factor as a robust and longitudinal predictor of various outcomes in past research (e.g., Froiland et al., 2013; Thomas et al., 2017). It is worth noting that parents perceived higher average STEM value than expectancies for their child. Parents in this study also more consistently reported high value of 
STEM, whereas expectancy was more heterogeneous. In particular, items assessing whether parents expected their preschool child would go into a math or science career were the lowest ranked items within this construct, perhaps reflecting that it is hard to imagine what a young child's career aspirations might entail. Thus, these null findings could reflect a measurement issue related to items that ask parents to make projections about their youngster's very distant career aspirations.

Another noteworthy finding was that parents in this sample did not appear to have different STEM motivation or involvement with their preschool-age girls compared to boys. Although we did not directly measure parents' endorsement of stereotypes, parent behaviors may be influenced by belief in gender stereotypes (Eccles, 1993). However, parents' gender stereotypes may begin to impact their behavior with children more around late elementary or middle school (Eccles et al., 1990). Thus, addressing gender stereotypes with parents of older students may be an effective way to encourage parents to promote STEM activities and interests with their children (Muenks et al., 2019; Rozek et al., 2015). However, our results do not suggest that parents of preschool-age children are impacted significantly by gender stereotypes in how they interact with their child, indicating minimal need to explicitly address this issue within preschool STEM interventions.

To summarize our EVT findings, parents espouse high value of STEM that should be maintained, in addition to heterogenous expectancies that might be enhanced via empowering parent communications and family engagement programs. Interventions that promote value are different from those that aim to enhance expectancy or reduce costs. For example, to increase parents' self-efficacy for facilitating science and math experiences, interventions should help parents gain information on engaging STEM activities and learn practical ways to embed talk 
about science and math in everyday routines (Garibay, 2007; Thippana, Elliott, Gehman, Libertus \& Libertus, 2020). In contrast, if we had seen high costs and barriers to doing STEM, then interventions might provide STEM-related materials so parents feel that doing science or math takes less effort. But for parents in this sample, costs and value were not the issues. Instead, parents' broad expectations appeared to be critical factors to address, since parent's self efficacy was higher for mothers in STEM careers and because there was heterogeneity in parents' expectations of the child's STEM success. For example, one experimental preschool study with low-income parents found that parental expectancies mediated gains in children's school readiness outcomes, but also demonstrated that parental expectations are malleable (LoughlinPresnal \& Bierman, 2017). Because parents bring conscious and unconscious perceptions about math and science from their own career pathway to parent-child interactions (Dorsen et al., 2006), it may be important to explicitly address these perceptions and explain evidence that all parents can be effectively supported to talk about counting, numeracy, and basic operations with their young child (e.g., Thippana et al., 2020).

\section{Limitations \& Future Research}

A key limitation of this study is its limited generalizability, because this U.S. sample includes mostly middle-class parents with Bachelor's degrees or higher and incomes above the poverty threshold. Further, our two methods for capturing these survey responses - registered users of an online parent resource and families waiting to enter a children's museum - suggest our sample of parents are already seeking information and experiences to promote their child's learning. There is a need to replicate these questions with more diverse families including those who are experiencing poverty, as these parents' perceptions may differ in ways that have implications for STEM programs. Second, our items measuring costs did not elucidate 
significant barriers preschool parents experience in doing science and math at home. Yet cost is an important factor and understudied factor (Flake et al., 2015). Therefore, future research should use additional approaches, including qualitative data, to better understand barriers and opportunity costs parents face in doing STEM. A third limitation is the reliance on parents' selfreport of involvement in STEM, rather than also including direct observation of parent-child interactions to examine the extent to which parents support STEM-related activities at home or within everyday routines. Future studies might consider how differences in both parents' and young children's motivation for STEM relate to: a) children's science and math achievement, b) the quality of parent-child discourse during STEM tasks, or c) children's immediate neural responses during STEM tasks (cf., Callanan et al., 2017; Kim et al., 2017; Ramani et al., 2015). These more diverse methodological approaches could also explain mechanisms for interest, persistence, and achievement in STEM.

\section{Conclusion \& Implications}

Taken together, these findings point to the potential power of interventions that rely on motivation theory to: a) explain to parents the value and relevance of STEM to children's academic and later career success, and b) enhance parents' self-efficacy to perceive themselves as capable of facilitating informal STEM learning within their everyday activities. There is heterogeneity in effectiveness of preschool parent education programs (Castro et al., 2015; Grindal et al., 2016) that might be improved if programs were tailored to address parents' unique perceptions, rather than simply providing information or STEM experiences that do not address parent-child motivation. For example, a short, baseline EVT survey could help informal science educators understand how to adapt their messaging to address particular parent concerns that could include limited parental self-efficacy, high perceived costs/barriers to doing STEM, or 
weak expectations for their child's science and math achievement. By tapping into parents' relatively high value of STEM and desire to help their child reach their full potential, future EVT-based interventions could help parents see how they can play a key role in immersing their child in STEM beginning in early childhood. 


\section{References}

Bandura, A. (1997). Self-efficacy: The exercise of control. New York, NY: Freeman.

Barnes, E., \& Puccioni, J. (2017). Shared book reading and preschool children's academic achievement: Evidence from the Early Childhood Longitudinal Study-Birth cohort. Infant and Child Development, 26(6), e2035.

Barnett, M. A., Paschall, K. W., Mastergeorge, A. M., Cutshaw, C. A., \& Warren, S. M. (2020). Influences of parent engagement in early childhood education centers and the home on kindergarten school readiness. Early Childhood Research Quarterly, 53, 260273.

Bekdemir, M. (2010). The pre-service teachers' mathematics anxiety related to depth of negative experiences in mathematics classroom while they were students. Educational Studies in Mathematics, 75(3), 311-328.

Bergey, B. W., Parrila, R. K., \& Deacon, S. H. (2018). Understanding the academic motivations of students with a history of reading difficulty: An expectancy-value-cost approach. Learning and Individual Differences, 67, 41-52.

Bullock, M., Sodian, B., \& Koerber, S. (2009). Doing experiments and understanding science: Development of scientific reasoning from childhood to adulthood. In W. Schneider \& M. Bullock (Eds.), Human development from early childhood to early adulthood: Findings from a 20 year longitudinal study (p. 173-197). Psychology Press.

Callanan, M. A., Castañeda, C. L., Luce, M. R., \& Martin, J. L. (2017). Family science talk in museums: Predicting children's engagement from variations in talk and activity. Child Development, 88(5), 1492-1504. 
Castro, M., Expósito-Casas, E., López-Martín, E., Lizasoain, L., Navarro-Asencio, E., \& Degol, J. L., Wang, M. T., Ye, F., \& Zhang, C. (2017). Who makes the cut? Parental involvement and math trajectories predicting college enrollment. Journal of Applied Developmental Psychology, 50, 60-70.

Degol, J. L., Wang, M. T., Ye, F., \& Zhang, C. (2017). Who makes the cut? Parental involvement and math trajectories predicting college enrollment. Journal of Applied Developmental Psychology, 50, 60-70.

Dorsen, J., Carlson, B., \& Goodyear, L. (2006). Connecting informal STEM experiences to career choices: Identifying the pathway. ITEST Learning Resource Center.

Dumas, D., McNeish, D., Sarama, J., \& Clements, D. (2019). Preschool mathematics intervention can significantly improve student learning trajectories through elementary school. AERA Open, 5(4), 2332858419879446.

Eccles, J. S. (1993). School and family effects on the ontogeny of children's interests, selfperceptions, and activity choices. In J. E. Jacobs \& R. M. Ryan (Eds.), Nebraska symposium on motivation, 1992: Developmental perspectives on motivation (pp. 145208). Lincoln: University of Nebraska Press.

Eccles, J. S. (2015). Gendered socialization of STEM interests in the family. International Journal of Gender, Science and Technology, 7(2), 116-132.

Eccles, J. S., Jacobs, J. E., \& Harold, R. D. (1990). Gender role stereotypes, expectancy effects, and parents' socialization of gender differences. Journal of Social Issues, 46(2), $183-201$ 
Fadigan, K. A., \& Hammrich, P. L. (2004). A longitudinal study of the educational and career trajectories of female participants of an urban informal science education program. Journal of Research in Science Teaching, 41(8), 835-860.

Fantuzzo, J., McWayne, C., Perry, M. A., \& Childs, S. (2004). Multiple dimensions of family involvement and their relations to behavioral and learning competencies for urban, lowincome children. School Psychology Review, 33(4), 467-480.

Fantuzzo, J., Tighe, E., \& Childs, S. (2000). Family Involvement Questionnaire: A Multivariate Assessment of Family Participation in Early Childhood Education. Journal of Educational Psychology, 92(2), 367-376.

Flake, J. K., Barron, K. E., Hulleman, C., McCoach, B. D., \& Welsh, M. E. (2015). Measuring cost: The forgotten component of expectancy-value theory. Contemporary Educational Psychology, 41, 232-244.

Froiland, J. M., Peterson, A., \& Davison, M. L. (2013). The long-term effects of early parent involvement and parent expectation in the USA. School Psychology International, 34(1), $33-50$.

Garibay, C. (2007). Para Los Ninos: Phase Two Evaluation. Garibay Group. Illinois.

Gaspard, H., Dicke, A. L., Flunger, B., Brisson, B. M., Häfner, I., Nagengast, B., \& Trautwein, U. (2015). Fostering adolescents' value beliefs for mathematics with a relevance intervention in the classroom. Developmental Psychology, 51(9), 1226.

Gaviria, J. L. (2015). Parental involvement on student academic achievement: A meta-analysis. Educational research review, 14, 33-46. 
Grindal, T., Bowne, J. B., Yoshikawa, H., Schindler, H. S., Duncan, G. J., Magnuson, K., \& Shonkoff, J. P. (2016). The added impact of parenting education in early childhood education programs: A meta-analysis. Children and Youth Services Review, 70, 238-249.

Grusec, J. E., \& Davidov, M. (2010). Integrating different perspectives on socialization theory and research: A domain-specific approach. Child Development, 81(3), 687-709.

Gunderson, E. A., \& Levine, S. C. (2011). Some types of parent number talk count more than others: relations between parents' input and children's cardinal-number knowledge. Developmental Science, 14(5), 1021-1032.

Haden, C. A. (2010). Talking about science in museums. Child Development Perspectives, $4(1), 62-67$.

Ho, E. S. C. (2010). Family influences on science learning among Hong Kong adolescents: What we learned from PISA. International Journal of Science and Mathematics Education, 8(3), 409-428.

Halpern, D., Aronson, J., Reimer, N., Simpkins, S., Star, J., and Wentzel, K. (2007). Encouraging Girls in Math and Science (NCER 2007-2003). Washington, DC: National Center for Education Research, Institute of Education Sciences, U.S. Department of Education. Retrieved from http://ncer.ed.gov.

Hollingsworth-Latimer, M. (2020). Purposeful School-To-Home Communication: Impact Of Instructional Newsletters On The Self-Efficacy Of Low-Socioeconomic Status Parents To Support Mathematics Learning At Home (Doctoral dissertation).

Hulleman, C. S., \& Harackiewicz, J. M. (2009). Promoting interest and performance in high school science classes. Science, 326(5958), 1410-1412. 
Jacobs, J. E., \& Eccles, J. S. (1992). The impact of mothers' gender-role stereotypic beliefs on mothers' and children's ability perceptions. Journal of Personality and Social Psychology, 63(6), 932-944.

Jeynes, W. (2012). A meta-analysis of the efficacy of different types of parental involvement programs for urban students. Urban Education, 47(4), 706-742.

Jiang, Y., Rosenzweig, E. Q., \& Gaspard, H. (2018). An expectancy-value-cost approach in predicting adolescent students' academic motivation and achievement. Contemporary Educational Psychology, 54, 139-152.

Jones, V. F., Brown, E. T., Molfese, V., Ferguson, M. C., Jacobi-Vessels, J., Bertsch, C., ... \& Davis, D. W. (2015). The development and initial assessment of Reach Out and Read plus Mathematics for use in primary care paediatrics. Early Child Development and Care, 185(5), 694-708.

Kim, M. H., Marulis, L. M., Grammer, J. K., Morrison, F. J., \& Gehring, W. J. (2017). Motivational processes from expectancy-value theory are associated with variability in the error positivity in young children. Journal of Experimental Child Psychology, 155, $32-47$.

Klein, A., Starkey, P., Clements, D., Sarama, J., \& Iyer, R. (2008). Effects of a pre-kindergarten mathematics intervention: A randomized experiment. Journal of Research on Educational Effectiveness, 1(3), 155-178.

Leyva, D., Tamis-LeMonda, C. S., Yoshikawa, H., Jimenez-Robbins, C., \& Malachowski, L. (2017). Grocery games: How ethnically diverse low-income mothers support children's reading and mathematics. Early Childhood Research Quarterly, 40, 63-76. 
Le, H. N., Ceballo, R., Chao, R., Hill, N. E., Murry, V. M., \& Pinderhughes, E. E. (2008). Excavating culture: Disentangling ethnic differences from contextual influences in parenting. Applied Development Science, 12(4), 163-175.

Lee, J., \& Shute, V. J. (2010). Personal and social-contextual factors in K-12 academic performance: An integrative perspective on student learning. Educational Psychologist, 45(3), 185-202.

Leichtman, M. D., Camilleri, K. A., Pillemer, D. B., Amato-Wierda, C. C., Hogan, J. E., \& Dongo, M. D. (2017). Talking after school: Parents' conversational styles and children's memory for a science lesson. Journal of Experimental Child Psychology, $156,1-15$.

Levine, S. C., Suriyakham, L. W., Rowe, M. L., Huttenlocher, J., \& Gunderson, E. A. (2010). What counts in the development of young children's number knowledge?. Developmental Psychology, 46(5), 1309.

Lummis, M., \& Stevenson, H. W. (1990). Gender differences in beliefs and achievement: A cross-cultural study. Developmental Psychology, 26(2), 254-263.

Ma, X., Shen, J., Krenn, H. Y., Hu, S., \& Yuan, J. (2016). A meta-analysis of the relationship between learning outcomes and parental involvement during early childhood education and early elementary education. Educational Psychology Review, 28(4), 771-801.

Manolitsis, G., Georgiou, G. K., \& Tziraki, N. (2013). Examining the effects of home literacy and numeracy environment on early reading and math acquisition. Early Childhood Research Quarterly, 28(4), 692-703. 
Master, A., \& Meltzoff, A. N. (2020). Cultural stereotypes and sense of belonging contribute to gender gaps in STEM. International Journal of Gender, Science, and Technology, $12,152-198$.

McClure, E. R., Guernsey, L., Clements, D. H., Bales, S. N., Nichols, J., Kendall-Taylor, N., \& Levine, M. H. (2017). STEM Starts Early: Grounding science, technology, engineering, and math education in early childhood. In Joan Ganz Cooney center at sesame workshop. Joan Ganz Cooney Center at Sesame Workshop. 1900 Broadway, New York, NY 10023.

McWayne, C. M., Cheung, K., Wright, L. E. G., \& Hahs-Vaughn, D. L. (2012). Patterns of school readiness among Head Start children: Meaningful within-group variability during the transition to kindergarten. Journal of Educational Psychology, 104(3), 862-878. https://doi.org/10.1037/a0028884

Napoli, A. R., \& Purpura, D. J. (2018). The home literacy and numeracy environment in preschool: Cross-domain relations of parent-child practices and child outcomes. Journal of Experimental Child Psychology, 166, 581-603.

Patall, E. A., Cooper, H., \& Robinson, J. C. (2008). Parent involvement in homework: A research synthesis. Review of Educational Research, 78(4), 1039-1101.

Patall, E. A., Pituch, K. A., Steingut, R. R., Vasquez, A. C., Yates, N., \& Kennedy, A. A. (2019). Agency and high school science students' motivation, engagement, and classroom support experiences. Journal of Applied Developmental Psychology, 62, 7792.

Perera, L. D. H., Bomhoff, E. J. \& Lee, G. H. Y. (2014). Parents' attitudes towards science and their children's science achievement. International Journal of Science Education, 36(18), 3021-3041. 
Pomerantz, E. M., Moorman, E. A., \& Litwack, S. D. (2007). The how, whom, and why of parents' involvement in children's academic lives: More is not always better. Review of Educational Research, 77(3), 373-410.

Powell, D. R., Son, S. H., File, N., \& Froiland, J. M. (2012). Changes in parent involvement across the transition from public school prekindergarten to first grade and children's academic outcomes. The Elementary School Journal, 113(2), 276-300.

Ramani, G. B., Rowe, M. L., Eason, S. H., \& Leech, K. A. (2015). Math talk during informal learning activities in Head Start families. Cognitive Development, 35, 15-33.

Rozek, C. S., Hyde, J. S., Svoboda, R. C., Hulleman, C. S., \& Harackiewicz, J. M. (2015). Gender differences in the effects of a utility-value intervention to help parents motivate adolescents in mathematics and science. Journal of Educational Psychology, 107(1), 195-206.

Rozek, C. S., Svoboda, R. C., Harackiewicz, J. M., Hulleman, C. S., \& Hyde, J. S. (2017). Utility-value intervention with parents increases students' STEM preparation and career pursuit. Proceedings of the National Academy of Sciences, 114(5), 909-914.

Silinskas, G., \& Kikas, E. (2019). Parental involvement in math homework: Links to children's performance and motivation. Scandinavian Journal of Educational Research, 63(1), 1737.

Šimunović, M., \& Babarović, T. (2020). The role of parents' beliefs in students' motivation, achievement, and choices in the STEM domain: a review and directions for future research. Social Psychology of Education, 23(3), 701-719. 
Skwarchuk, S. L. (2009). How do parents support preschoolers' numeracy learning experiences at home?. Early Childhood Education Journal, 37(3), 189-197. DOI: https://doi.org/10.1007/s10643-009-0340-1

Skwarchuk, S. L., Sowinski, C., \& LeFevre, J. A. (2014). Formal and informal home learning activities in relation to children's early numeracy and literacy skills: The development of a home numeracy model. Journal of Experimental Child Psychology, 121, 63-84.

Tabachnick, B. G., Fidell, L. S., \& Ullman, J. B. (2007). Using multivariate statistics (Vol.5). Boston, MA: Pearson.

Tenenbaum, H. R., Snow, C. E., Roach, K. A., \& Kurland, B. (2005). Talking and reading science: Longitudinal data on sex differences in mother-child conversations in lowincome families. Journal of Applied Developmental Psychology, 26(1), 1-19.

Thippana, J., Elliott, L., Gehman, S., Libertus, K., \& Libertus, M. E. (2020). Parents' use of number talk with young children: Comparing methods, family factors, activity contexts, and relations to math skills. Early Childhood Research Quarterly, 53, 249-259.

Tiedemann, J. (2000). Parents' gender stereotypes and teachers' beliefs as predictors of children's concept of their mathematical ability in elementary school. Journal of Educational Psychology, 92(1), 144-151.

von Hippel, P. T., Workman, J., \& Downey, D. B. (2018). Inequality in reading and math skills forms mainly before kindergarten: A replication, and partial correction, of "Are schools the great equalizer?" Sociology of Education, 91(4), 323-357.

Wang, M. T., \& Degol, J. (2013). Motivational pathways to STEM career choices: Using expectancy-value perspective to understand individual and gender differences in STEM fields. Developmental Review, 33(4), 304-340. 
West, J., Tarullo, L., Aikens, N., Malone, L., \& Carlson, B. L. (2011). FACES 2009 Study Design. OPRE Report 2011-9. Washington, DC: Office of Planning, Research and Evaluation, Administration for Children and Families, U.S. Department of Health and Human Services.

Wigfield, A., \& Eccles, J. S.(2000). Expectancy-value theory of achievement motivation. Contemporary Educational Psychology, 25(1), 68-81.

Wigfield, A., \& Gladstone, J. R. (2019). What Does Expectancy-value Theory Have to Say about Motivation and Achievement in Times of Change and Uncertainty?. In E.N. Gonida and M. S. Lemos (Eds.) Motivation in Education at a Time of Global Change: Theory, Research, and Implications for Practice. Emerald Publishing Limited: Bingley, UK.

Zuckerman, B. (2009). Promoting early literacy in pediatric practice: twenty years of reach out and read. Pediatrics, 124(6), 1660-1665. 
Table 1

Demographic Characteristics for Overall Sample

\begin{tabular}{|c|c|c|}
\hline \multirow{2}{*}{\multicolumn{2}{|c|}{$\begin{array}{l}\text { Variable } \\
\text { Parent characteristics }\end{array}$}} & $\mathrm{n}(\%)$ \\
\hline & & \\
\hline \multicolumn{3}{|c|}{ Maternal education } \\
\hline & & $1(1)$ \\
\hline- & Eighth grade or less & $5(3)$ \\
\hline - & Less than high school & $12(6)$ \\
\hline- & High school degree & $21(11)$ \\
\hline- & Some college or vocational training & $14(8)$ \\
\hline - & Associates degree & $43(23)$ \\
\hline- & Bachelor's degree & 17(9) \\
\hline - & Some graduate school but no degree & $17(9)$ \\
\hline- & Master's or postgraduate degree (MA or MS) & $44(24)$ \\
\hline- & Professional degree (e.g., MD, $\mathrm{PhD}, \mathrm{JD})$ & $28(15)$ \\
\hline \multicolumn{3}{|c|}{ Paternal education } \\
\hline & & $3(2)$ \\
\hline- & Eighth grade or less & $11(6)$ \\
\hline- & Less than high school & $22(12)$ \\
\hline- & High school degree & $19(10)$ \\
\hline- & Some college or vocational training & $10(5)$ \\
\hline & Associates degree & $49(26)$ \\
\hline & Bachelor's degree & \\
\hline- & Some graduate school but no degree & $32(17)$ \\
\hline - & Master's or postgraduate degree (MA or MS) & $32(1 /)$ \\
\hline- & Professional degree (e.g., MD, $\mathrm{PhD}, \mathrm{JD}$ ) & $30(16)$ \\
\hline \multicolumn{3}{|c|}{ Parent reported household income } \\
\hline & & $11(6)$ \\
\hline- & 11,000 or less & $5(3)$ \\
\hline- & $11,001-20,000$ & $9(5)$ \\
\hline - & $20,001-30,000$ & $20(11)$ \\
\hline - & $30,001-40,000$ & $31(17)$ \\
\hline - & $40,001-70,000$ & $51(17)$ \\
\hline - & $70,001-100,000$ & $24(13)$ \\
\hline - & $100,001-150,000$ & $32(18)$ \\
\hline- & 150,001 or more & $48(27)$ \\
\hline \multicolumn{3}{|c|}{ Self-reported STEM career } \\
\hline \multicolumn{2}{|c|}{ Mother - Yes } & $82(44)$ \\
\hline \multicolumn{2}{|c|}{ Father - Yes } & $88(48)$ \\
\hline \multicolumn{3}{|c|}{ Child characteristics } \\
\hline Child & (female) & $89(48)$ \\
\hline \multicolumn{3}{|c|}{ Child race/ethnicity } \\
\hline & & $21(11)$ \\
\hline- & Black/African American & $47(25)$ \\
\hline - & Hispanic/Latino & $87(48)$ \\
\hline- & White/Caucasian & $19(10)$ \\
\hline- & Asian & $11(6)$ \\
\hline & Other & \\
\hline \multicolumn{3}{|c|}{ Language(s) spoken at home } \\
\hline & & $112(60)$ \\
\hline- & English only & $44(23)$ \\
\hline- & Spanish/English & $10(5)$ \\
\hline- & Chinese/English & $22(12)$ \\
\hline- & Other & \\
\hline
\end{tabular}


Table 2

EFA Results Comparing the Fit of Different Factor Solutions

\begin{tabular}{lll}
\hline Model & AIC & BIC \\
\hline 1 factor & 23336.76 & 23737.27 \\
2 factor & 22702.25 & 23232.92 \\
3 factor & 22229.25 & 22886.75 \\
4 factor & 21935.66 & 22716.65 \\
5 factor & $\mathbf{2 1 7 3 9 . 7 2}$ & $\mathbf{2 2 6 4 0 . 8 5}$
\end{tabular}

Note. Eigenvalues were greater than 2.00 for the first four factors and was 1.98 for the fifth factor. 
Table 3

Survey Items Grouped by Final Factors

\begin{tabular}{|c|c|c|c|c|c|}
\hline & $\begin{array}{l}\text { Parent } \\
\text { Involve }\end{array}$ & $\begin{array}{l}\text { Parent } \\
\text { Expect } \\
\text { Child }\end{array}$ & $\begin{array}{l}\text { Parent } \\
\text { Self } \\
\text { Efficacy }\end{array}$ & $\begin{array}{l}\text { Parent } \\
\text { Value }\end{array}$ & $\begin{array}{l}\text { Parent } \\
\text { Costs }\end{array}$ \\
\hline \multicolumn{6}{|l|}{ Parent Involvement } \\
\hline & $0.71^{*}$ & $-0.18^{*}$ & -0.02 & $0.16^{*}$ & -0.05 \\
\hline $\begin{array}{l}\text { - How many times in the past week have you talked to your child about shapes (e.g., } \\
\text { triangle, square)? }\end{array}$ & $0.76^{*}$ & -0.14 & 0.01 & $-0.13^{*}$ & -0.03 \\
\hline $\begin{array}{l}\text { - How many times in the past week have you compared sizes of objects or toys with your } \\
\text { child (e.g., big, little, shorter)? } \\
\text { - How many times in the past week have you counted different things with your child }\end{array}$ & $0.68^{*}$ & -0.08 & 0.05 & 0.02 & 0.01 \\
\hline $\begin{array}{l}\text { (e.g., spoons, grapes, cans)? } \\
\text { How many times in the past week have you played counting games with your child } \\
\text { (e.g., singing songs with numbers)? }\end{array}$ & $0.65^{*}$ & -0.13 & 0.07 & 0.04 & 0.02 \\
\hline $\begin{array}{l}\text { How many times in the past week have you talked with your child about how to make } \\
\text { objects or toys move faster/slower or in different directions (e.g., cars roll faster on } \\
\text { smooth surfaces)? }\end{array}$ & $0.72 *$ & -0.07 & -0.01 & 0.05 & 0.04 \\
\hline $\begin{array}{l}\text { - How many times in the past week have you talked with your child about technology or } \\
\text { tools that help us do things? }\end{array}$ & $0.65^{*}$ & 0.08 & 0.09 & -0.05 & 0.04 \\
\hline $\begin{array}{l}\text { How many times in the past week have you talked with your child about weather, } \\
\text { seasons, or the environment? }\end{array}$ & $0.62 *$ & 0.09 & -0.09 & -0.02 & -0.04 \\
\hline $\begin{array}{l}\text { - How many times in the past week have you talked with your child about plants, } \\
\text { animals, or other living things? }\end{array}$ & $0.59^{*}$ & 0.07 & 0.01 & -0.08 & -0.13 \\
\hline $\begin{array}{l}\text { need to be healthy? } \\
\text { How many times in the past week have you played board games or card games with }\end{array}$ & $0.56 *$ & 0.04 & -0.01 & 0.03 & 0.00 \\
\hline your child? & $0.45^{*}$ & 0.04 & -0.10 & 0.02 & 0.11 \\
\hline \multicolumn{6}{|l|}{ Parent Expectations of Child } \\
\hline & -0.08 & $0.60^{*}$ & 0.02 & $0.23 *$ & 0.08 \\
\hline - I expect my child to do very well in science. & $-0.22 *$ & $0.54 *$ & 0.03 & 0.17 & 0.08 \\
\hline - I expect my child to do very well in math. & -0.05 & $0.80^{*}$ & -0.06 & 0.07 & -0.01 \\
\hline - I think my child will receive good math grades when in kindergarten. & 0.04 & $0.82 *$ & -0.05 & -0.08 & -0.11 \\
\hline - I think my child will receive good science grades when in kindergarten & 0.09 & $0.35^{*}$ & 0.06 & 0.07 & 0.03 \\
\hline $\begin{array}{l}\text { - I think my child will go into a math-related career. } \\
\text { - } \quad \text { I think my child will go into a science-related career. }\end{array}$ & $0.16^{*}$ & $0.40^{*}$ & 0.11 & 0.10 & 0.04 \\
\hline
\end{tabular}




\begin{tabular}{|c|c|c|c|c|c|c|}
\hline \multicolumn{7}{|c|}{ Parent Self-Efficacy } \\
\hline & & $0.23 *$ & 0.16 & 0.73* & -0.06 & 0.05 \\
\hline - & When I help my child learn science, I feel comfortable. & $0.34^{*}$ & 0.22 & $0.44 *$ & $-0.15^{*}$ & 0.01 \\
\hline - & I have the materials I need to support my child's science learning at home. & -0.00 & 0.09 & $0.69 *$ & -0.02 & -0.10 \\
\hline & When I help my child learn math, I feel comfortable. & $0.18^{*}$ & $0.25^{*}$ & $0.33^{*}$ & -0.14 & -0.06 \\
\hline & I have the materials I need to support my child's math learning at home. & 0.11 & -0.00 & 0.48 * & $0.37 *$ & 0.06 \\
\hline & I am interested in science. & 0.15 & -0.05 & $0.45 *$ & $0.43 *$ & 0.10 \\
\hline & I am interested in math. & $018 *$ & $0.35^{*}$ & $0.36 *$ & 0.03 & -0.13 \\
\hline & I know how to support my child's science learning. & $0.18^{\circ}$ & & & 0.00 & -0.13 \\
\hline & I am confident that I can support my child's math learning. & -0.05 & $0.41^{*}$ & $0.30^{*}$ & 0.05 & $-0.29 *$ \\
\hline & I am confident that I can support my child's science learning. & $0.15^{*}$ & $0.41^{*}$ & $0.28^{*}$ & 0.12 & $-0.24^{*}$ \\
\hline & I know how to support my child's math learning. & 0.00 & $0.42 *$ & $0.38^{*}$ & -0.02 & $-0.18^{*}$ \\
\hline \multicolumn{7}{|c|}{ Parent Values } \\
\hline & & -0.01 & 0.06 & -0.10 & $0.77 *$ & -0.07 \\
\hline - & $\begin{array}{l}\text { It is important to have good math knowledge and skills to get any good job in today's } \\
\text { world. }\end{array}$ & -0.00 & 0.09 & -0.05 & $0.71 *$ & 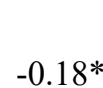 \\
\hline & In the job market it helps to have good math knowledge and skills. & $0.24 *$ & 0.03 & 0.02 & $0.69 *$ & 0.04 \\
\hline & $\begin{array}{l}\text { It is important to have good scientific knowledge and skills to get any good job in } \\
\text { today's world. }\end{array}$ & & & & & \\
\hline & In the job market it helps to have good scientific knowledge and skills. & 0.08 & -0.01 & 0.11 & $0.71^{*}$ & -0.04 \\
\hline & It is important for my child to learn math. & -0.01 & 0.15 & 0.02 & $0.51^{*}$ & -0.12 \\
\hline & It is important for my child to learn about science. & $0.16^{*}$ & 0.16 & 0.11 & $\mathbf{0 . 4 5 *}$ & 0.01 \\
\hline \multicolumn{7}{|c|}{ Parent Costs } \\
\hline & & $-0.17 *$ & 0.05 & 0.08 & -0.07 & $0.54 *$ \\
\hline & $\begin{array}{l}\text { Because of the other things I have to do, I don't have enough time for doing math with } \\
\text { my child. } \\
\text { Because of the other things I have to do, I don't have enough time for doing science }\end{array}$ & $-0.21 *$ & -0.03 & $0.15^{*}$ & -0.07 & 0.53 * \\
\hline & $\begin{array}{l}\text { with my child. } \\
\text { It takes too much effort for me to help my child do well in math. }\end{array}$ & 0.02 & -0.06 & -0.01 & 0.05 & 0.91 * \\
\hline & It takes too much effort for me to help my child do well in science. & $-0.11 *$ & $-0.13 *$ & 0.01 & 0.06 & $0.88^{*}$ \\
\hline & $\begin{array}{l}\text { It requires too much effort for me to get materials I need to do math activities with my } \\
\text { child. }\end{array}$ & 0.09 & 0.09 & -0.13 & 0.02 & $0.68^{*}$ \\
\hline - & $\begin{array}{l}\text { It requires too much effort for me to get materials I need to do science activities with } \\
\text { my child. }\end{array}$ & 0.00 & 0.04 & $-0.18^{*}$ & 0.05 & $0.63 *$ \\
\hline - & Helping my child with science activities makes me feel stress. & 0.08 & -0.01 & $-0.55^{*}$ & -0.10 & 0.33* \\
\hline - & Helping my child with math activities makes me feel stress. & $0.29 *$ & 0.05 & $-0.57 *$ & -0.12 & $0.37^{*}$ \\
\hline
\end{tabular}


Note. Bold denotes items were used on that factor during the SEM analyses. Three items with cross loadings on multiple factors were dropped, including: a) I am confident that I can support my child's math learning. b) I am confident that I can support my child's science learning. c) I know how to support my child's math learning. These items are listed under "parent self-efficacy" but are not bolded as they were not included in SEM analyses. Factors listed above follow the theoretical order (Involvement, Expectancies, Values, Cost) of the EVC theory; order does not denote variance accounted for. 
Table 4

Parent Involvement Descriptives by Child Gender

\begin{tabular}{lllll}
\hline Variables & $\begin{array}{l}\text { n } \\
\text { (all) }\end{array}$ & $\begin{array}{l}\text { Mean } \\
\text { (SD) }\end{array}$ & $\begin{array}{l}\text { Boys M } \\
\text { (SD) }\end{array}$ & $\begin{array}{l}\text { Girls M } \\
\text { (SD) }\end{array}$ \\
\hline $\begin{array}{l}\text { Parent expectations of child } \\
\text { Parent expectations of self (self- }\end{array}$ & 196 & $5.57(1.20)$ & $5.55(1.24)$ & $5.65(1.10)$ \\
efficacy) & 187 & $5.82(1.37)$ & $5.91(1.38)$ & $5.73(1.38)$ \\
Parent values & 187 & $6.36(0.84)$ & $6.44(0.81)$ & $6.27(0.85)$ \\
Parent costs & 196 & $2.32(1.62)$ & $2.21(1.61)$ & $2.42(1.66)$ \\
STEM involvement & 208 & $2.59(0.94)$ & $2.66(0.95)$ & $2.58(0.92)$ \\
Literacy involvement & 208 & $2.92(0.87)$ & $2.94(0.82)$ & $2.91(0.89)$ \\
\hline
\end{tabular}


Table 5

Correlations between factors, predictors and covariates

\begin{tabular}{|c|c|c|c|c|c|c|c|c|}
\hline Variables & 1 & 2 & 3 & 4 & 5 & 6 & 7 & 8 \\
\hline 1. Parent involvement & 1.00 & & & & & & & \\
\hline 2. Parent expectations of child & $0.20 *$ & 1.00 & & & & & & \\
\hline 3. Parent expectations of self (self-efficacy) & $0.40 *$ & $0.60^{*}$ & 1.00 & & & & & \\
\hline 4. Parent values & $0.30 *$ & $0.44^{*}$ & $0.42 *$ & 1.00 & & & & \\
\hline 5. Parent costs & $-0.15^{\text {T }}$ & $-0.36^{*}$ & $-0.30 *$ & $-0.20 *$ & 1.00 & & & \\
\hline 6. Child gender & 0.04 & -0.05 & 0.07 & 0.07 & -0.04 & 1.00 & & \\
\hline 7. Child language (mono- or bilingual) & -0.04 & 0.01 & 0.03 & 0.02 & $-0.15^{*}$ & -0.02 & 1.00 & \\
\hline 8. Maternal career (STEM or non-STEM) & 0.04 & 0.01 & $0.13 *$ & 0.06 & -0.01 & 0.02 & 0.01 & 1.00 \\
\hline 9. Parent reported income & -0.08 & -0.22 & -0.12 & -0.16 & 0.16 & -0.06 & $0.12 *$ & -0.05 \\
\hline
\end{tabular}

Note. For child gender, female is the reference group (0); for child language, English is the reference group; for STEM or non-STEM career, non-STEM career is the reference group.

${ }^{*} p<.05 ;{ }^{\top} p<.10$ 


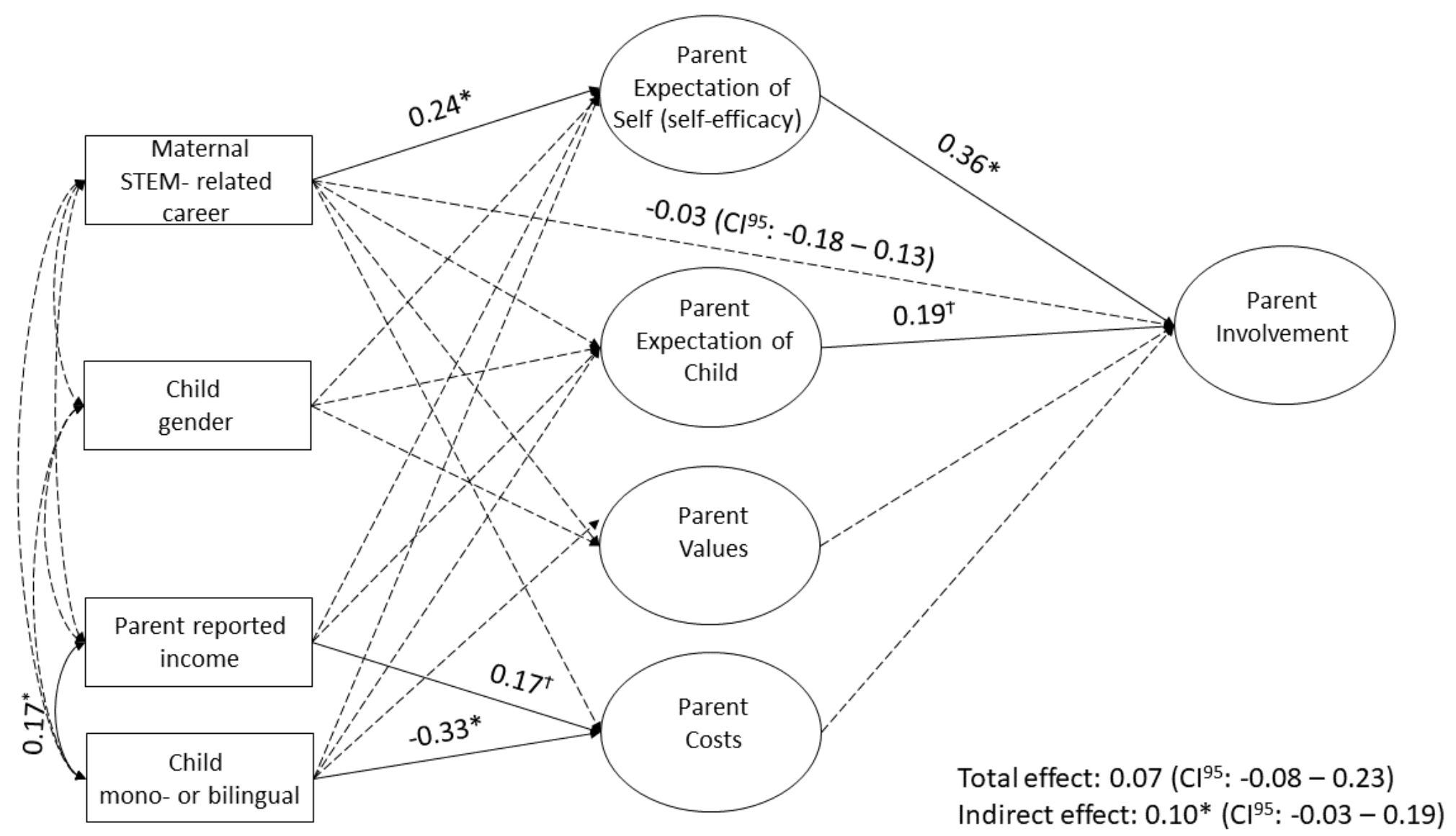

Figure 1. Full Structural Equation Mediation Model of associations between maternal career, STEM Expectancies, Value, Cost, and Parent Involvement. Note. Standardized values are included for significant pathways. Non-significant pathways are denoted by a dashed line. Item loadings on the factors are suppressed to simplify the figure, as were tested mediations between Maternal STEMrelated career and all other factors. The association between Parent expectation of child is significant $(p=.04)$ when maternal career is not included in the model (RQ1). When maternal career is included, the standardized value is unchanged (0.19), but the p-value changes to 0.09 . 
